\title{
PENGARUH SUHU BAHAN BAKAR TERHADAP EMISI GAS BUANG PADA MESIN BENSIN 1800 cc
}

\author{
${ }^{1}$ Yuniarto Agus Winoko ${ }^{2}$ Santoso ${ }^{3}$ Khambali \\ 1,2,3 Teknik Mesin, Politeknik Negeri Malang \\ 11dhimazyuni@gmail.com
}

(Artikel diterima: Februari 2020, direvisi: April 2020, diterima untuk terbit: Juli 2020)

\begin{abstract}
Abstrak - The perfect combustion process can occur if the high compression pressure, proper ignition time, and suitable fuel air mixture. Suitable fuel air mixture can be obtained by heating the fuel to reduce its viscosity so the mixture is more homogeneous. Fuel heating can be done in various ways, such as by utilizing the heat of radiator water coming out of the engine. The purpose of the study is determine effect of the fuel heating to exhaust emission of gasoline engine $1800 \mathrm{cc}$. The study uses experimental with the variable used pertamax with temperature $40^{\circ}, 50^{\circ}, 60^{\circ}$, and $70^{\circ}$. The dependent variable in the study is exhaust emission of gasoline engine. The results of the study indicate that fuel heating affects exhaust emissions. Temperature that affects the exhaust gas emissions at $60^{\circ} \mathrm{C}$ with the use of pertamax fuel.
\end{abstract}

Kata kunci: automatic heating, exhaust emission, and temperature.

\section{Pendahuluan}

Pada motor bensin proses pembakaran campuran bahan bakar dan udara terjadi di ruang bakar, agar campuran udara dan bahan bakar tersebut dapat terbakar dengan sempurna maka suhu dan tekanannya harus sesuai, kondisi ini akan meningkatkan efisiensi pembakaran, peningkatnya dilakukan dengan memanfaatkan panas yang keluar dari air radiator. Agar pemanasan terkontrol maka dibuat alat yang dapat mengatur suhu tersebut secara otomatis. Salah satunya bisa dengan memanaskan bahan bakar yang akan masuk ke ruang bakar. Hal ini disebabkan karena meningkatnya nilai kalor dan viskositas dari bahan bakar akan turun, sehingga proses pencampuran bahan bakar dengan udara dapat bercampur dengan sempurna. Proses pembakaran didalam ruang bakar tersebut akan lebih efektif serta menghasilkan emisi gas buang yang lebih baik.

Alat pemanas otomatis dengan pemanfaatan fluida panas radiator untuk memanaskan bahan bakar karena suhu output air radiator yang lebih tinggi dari suhu bahan bakar. Perbedaan suhu antara bahan bakar dengan fluida panas radiator ini maka diharapkan pemanasan bahan bakar dapat terjadi dengan baik, serta dapat mengetahui suhu optimum pembakaran yang akan menghasilkan emisi gas buang yang tidak mencemari lingkungan.

Arif N, Husin B, Danar S W, (2010:10) dalam penelitiannya yang berjudul "Pengaruh Variassi Putaran Mesin dan Pemanasan Bahan Bakar Bensin, Melalui Pipa Kapiler Bersirip Radial didalam Upper Tank Radiator terhadap Konsumsi Bahan Bensin pada Mesin Toyota" menyimpulkan, ada penurunan pemanasan bahan bakar bensin melalui pipa kapiler bersirip radial di dalam uppertank radiator terhadap emisi gas buang $\mathrm{CO}$ dan $\mathrm{HC}$ pada mesin Toyota Kijang. Penurunan emisi gas buang $\mathrm{CO}$ dan $\mathrm{HC}$ terbesar yaitu pada percobaan dengan menggunakan pemanasan 3 pipa tembaga dengan jarak antar sirip $10 \mathrm{~mm}$. Selisih emisi gas buang CO sebesar 2,54\% volume atau sebesar $85 \%$ dan emisi gas buang HC sebesar 139,667 ppm volume atau sebesar $72 \%$. Penelitian ini berbeda dengan penelitian saya karena penelitian ini menggunakan pipa kapiler bersirip yang di letakan pada uppertank radiator sedangkan penelitian saya menggunakan sistem heat exchanger yang berada diantara radiator dan karburator.
Hariyono (2007:71) dalam penelitian yang berjudul "Pengaruh Pemanasan Bahan Bakar Dengan Media Radiator Terhadap Konsumsi Bahan Bakar dan Kandungan CO Gas Buang Pada Motor Bensin" menyimpulkan, pemanasan bahan bakar dapat membantu mengurangi konsumsi bahan bakar dan menurunkan kandungan CO gas buang pada motor bensin. Pada penelitian ini konsumsi bahan bakar pertamax mengalami penurunan masing-masing sebesar $9.94 \%$ untuk saluran $1,9.58 \%$ untuk saluran 2 , dan $10.22 \%$ untuk saluran 3. sedangkan kandungan CO gas buang pada $46.17 \%$ untuk saluran 1, $20.66 \%$ untuk saluran 2, dan $18.98 \%$ untuk saluran 3. Penelitian ini berbeda dengan penelitian saya karena pada penelitian ini menggunakan 3 pipa saluran bahan bakar yang mana saluran itu diletakan pada radiator dan pada penelitian saya mengambil air radiator untuk dimasukkan dalam alat pemanas yang terdapat saluran bahan bakarnya.

Didik A (2017:10) dalam penelitiannya yang berjudul "Pengaruh Pemanasan Bahan Bakar Melalui Pipa Bersirip Radial Pada Uppertank Radiator dan Penambahan Etanol Dalam Bahan Bakar Pertalite Terhadap Emisi Gas Buang Pada Mobil Suzuki APV" menyimpulkan, emisi gas buang $\mathrm{CO}$ dan $\mathrm{HC}$ menurun. Jumlah emisi terendah pada saat pemanasan bahan bakar menggunakan pipa bersirip radial dengan jarak antar sirip $10 \mathrm{~mm}$, CO sebesar 0,596\% volume atau sebesar 0,44\% dan HC sebesar 260,00 ppm atau sebesar $18,06 \%$. Penelitian ini berbeda dengan penelitian saya karena penelitian ini menggunakan pipa kapiler bersirip yang di letakan pada uppertank radiator sedangkan penelitian saya menggunakan sistem heat exchanger yang berada diantara radiator dan karburator.

\section{TINJAUAN PUSTAKA}

\section{A. BBM (Bahan Bakar Minyak)}

Bahan Bakar adalah suatu materi apapun yang bisa diubah menjadi energi. Biasanya bahan bakar mengandung energi panas yang dapat dilepaskan dan dimanipulasi. Kebanyakan bahan bakar digunakan manusia melalui proses pembakaran di mana bahan bakar tersebut akan melepaskan panas setelah direaksikan dengan oksigen di udara. Bahan bakar yang dimaksud dalam hal ini adalah pertalite dan pertamax. Pertamax adalah bahan bakar ramah lingkungan beroktan tinggi hasil penyempurnaan produk pertamina 
sebelumnya yaitu premix yang mempunyai RON 92 (www.pertamina.com), dengan nilai RON yang lebih tinggi dari pertalite maka pertamax akan terbakar lebih sempurna.

\section{B. Teori Pembakaran}

Pembakaran dalam mesin Otto di kenal dengan stoikiometri untuk mendapatkan perbandingan yang ideal antara udara dan bahan bakar. Stoikiometri sendiri adalah angka teoritis yang menyatakan perbandingan udara dan bahan bakar ideal, sehingga untuk pembakaran yang sempurna reaksi pembakarannya menghasilkan $\mathrm{H}_{2} \mathrm{O}$ dan $\mathrm{CO}_{2}$ tanpa gas seperti CO, NOx, dan HC.

Persamaan reaksi pembakaran :

$$
\begin{aligned}
\mathrm{C}_{8} \mathrm{H}_{18}+12,5\left(\mathrm{O}_{2}+3,76 \mathrm{~N}_{2}\right) & \longrightarrow 8 \mathrm{CO}_{2}+9 \mathrm{H}_{2} \mathrm{O}+ \\
12,5\left(3,76 \mathrm{~N}_{2}\right)+\text { Energi } & \longrightarrow
\end{aligned}
$$

Pembakaran tidak sempurna adalah proses pembakaran yang terjadi akibat ada campuran bahan bakar yang mengalami penyalaan sendiri yang bisanya tidak disebabkan oleh percikan bunga api dari busi. Sehingga untuk pembakaran tidak sempurna reaksi pembakarannya menghasilkan gas seperti CO, NOx, dan HC.

$$
\begin{gathered}
\mathrm{C}_{8} \mathrm{H}_{18}+\mathrm{O}_{2}+3,76 \mathrm{~N}_{2} \\
\mathrm{O}_{2}+\mathrm{NO}+3,76 \mathrm{~N}_{2}+\text { energi }
\end{gathered}
$$

\section{Perpindahan Kalor}

Perpindahan kalor adalah ilmu yang untuk meramalkan perpindahan energi yang terjadi karena adanya perbedaan suhu diantara benda atau material. Energi yang berpindah itu dinamakan kalor atau panas. Ilmu perpindahan kalor sendiri tidak hanya menjelaskan tentang berpindahnya energi kalor dari satu benda ke benda lain, tapi juga dapat meramalkan laju perpindahan pada kondisi-kondisi tertentu. Dalam penelitian ini perpindahan kalor yang digunakan adalah secara konduksi dan secara konveksi. Perpindahan kalor secara konduksi ini terjadi karena adanya perpindahan energi dari partikel yang memiliki energi lebih tinggi ke partikel yang lebih rendah dikarenakan adanya interaksi antara kedua partikel. Perpindahan kalor secara konveksi terjadi antara permukaan padat dengan fluida yang mengalir disekitarnya, dengan menggunakan media penghantar berupa fluida (cairan/gas).

\section{Emisi Gas Buang}

Emisi gas buang pembakaran tidak sempurna adalah toksi dan sebagian berupa gas rumah kaca, sehingga perlu direduksi. Strategi pengurangan gas buang motor bakar dapat dilakukan saat sebelum proses pembakaran berlangsung, saat proses pembakaran dan setelah proses pembakaran selesai. Terdapat 5 unsur dalam gas buang yang perlu di ukur, diantaranya senyawa $\mathrm{HC}, \mathrm{CO}, \mathrm{CO}_{2}, \mathrm{O}_{2}$, dan senyawa $\mathrm{NO}_{x}$, kecilnya konsenttrasi beberapa Negara hanya mengukur 4 unsur dalam gas buang yaitu senyawa $\mathrm{HC}, \mathrm{CO}, \mathrm{CO}_{2}$, dan $\mathrm{O}_{2}$ (Yuniarto,2017:106). Gas karbon monoksida (CO) adalah gas yang tidak stabil dan cenderung mudah bereaksi dengan unsur lain, kadar emisi untuk gas karbon monoksida pada motor bakar konvensional berkisar antara 3,5\%. Bensin adalah bahan bakar yang berasal dari senyawa hidrokarbon, sehingga setiap HC pada motor bensin menunjukan terjadinya proses bahan bakar yang tidak terbakar, pada motor bakar konvensional pengurangan $\mathrm{HC}$ dilakukan dengan menambah oksigen diluar ruang bakar atau memanfaatkan tingginya suhu pembakaran (panas). Karbondioksida $\left(\mathrm{CO}_{2}\right)$ merupakan sejenis senyawa kimia yang terdiri dari dua atom oksigen yang terikat secara kovalen dengan sebuah atom karbon, karbondioksida ini berbentuk gas pada keadaan temperatur dan tekanan standart serta hasil dari pembakaran senyawa organik dan juga merupakan hasil samping pembakaran bahan bakar fosil.

\section{METODOLOGI}

\section{A. Prinsip Kerja Alat}

Alat pemanas bahan bakar ini memanfaatkan panas yang terbuang dari sistem pendinginan mesin yang dibawa oleh air radiator, sehingga pemanasan ini tidak membebani kinerja mesin. Untuk mengefisiensikan pemanasan ini maka dilakukan pengaturan secara elektronik.

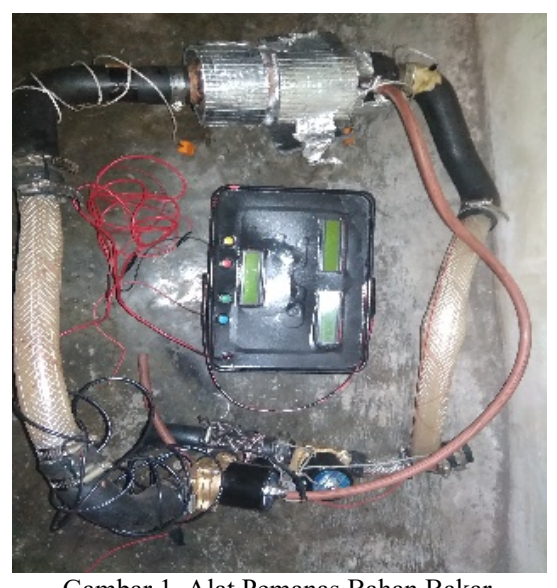

Gambar 1. Alat Pemanas Bahan Bakar

Prinsip kerja alat pemanas bahan bakar otomatis ini memanfaatkan sirkulasi dari sistem pendingin kendaraan, kalor yang di buang ke lingkungan melewati radiator di manfaatkan sebagian sebagai pemanas bahan bakar. Cairan air radiator yang baru keluar dari sistem di masukkan kedalam alat penghantar panas ke saluran yang melewati pipa kecil di dalamnya, lalu dalam saat bersamaan bahan bakar di alirkan ke dalam tabung yang dilewati pipa yang dilewati fluida panas tersebut. Lalu untuk saluran keluar dari pipa yang di lewati air radiator di salurkan kembali ke sirkulasi pendinginan mesin melalui saluran yang akan masuk kedalam sistem. Untuk mendeteksi suhu pemanasan bahan bakar ini menggunakan sensor suhu yang akan diletakkan pada saluran keluar bahan bakar dari alat tersebut, sedangkan untuk mengatur suhu menggunakan selenoid valve. Selenoid valve ini mengatur sirkulasi air radiator yang melewati alat tersebut jika suhu bahan bakar belum tercapai maka selenoid akan membuka dan jika suhu yang di inginkan sudah tercapai maka selenoid akan tertutup. Hasil dari pengaturan suhu yang dilakukan akan di tampilkan dalam layar lcd dalam box sistem.

\section{B. Diagram Alir}

Diagram alir penelitian ini dapat di lihat sebagai berikut: 


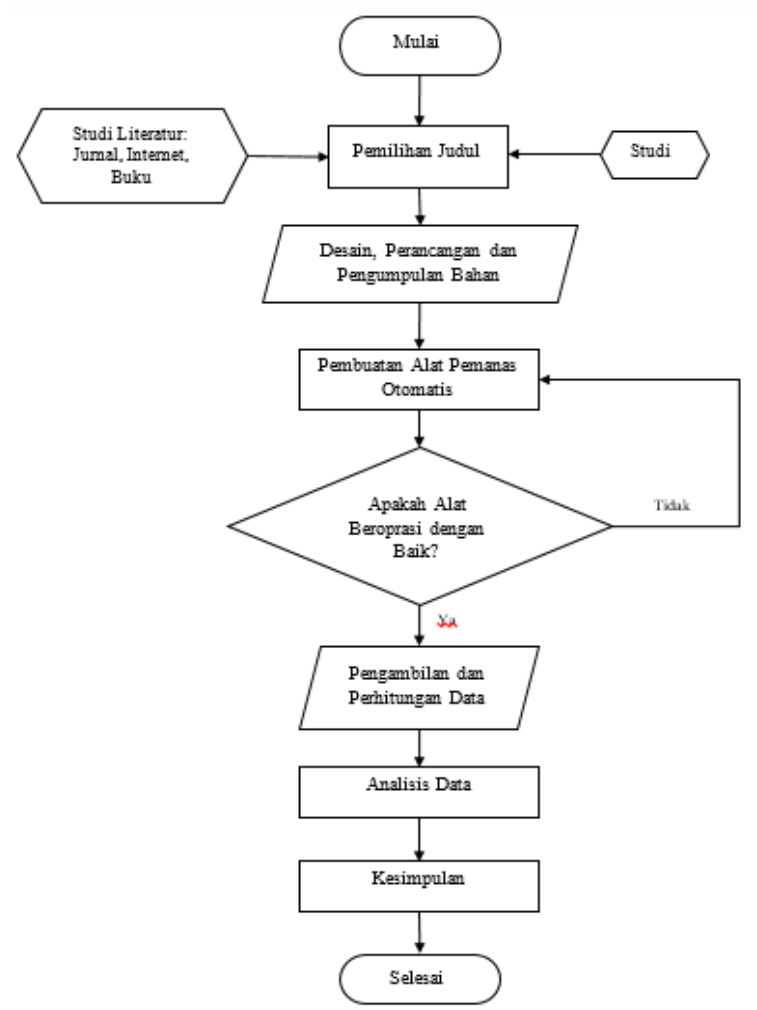

Gambar 2 Diagram Alir Penelitian

\section{Variabel Penelitian}

Dalam penelitian ini terdapat beberapa variabel yang telah ditentukan diantaranya adalah:

\section{Variabel Bebas}

Variabel bebas adalah kondisi yang mempengaruhi munculnya suatu gejala. Dalam penelitian ini yang menjadi variabel bebas adalah variasi jenis bahan bakar yaitu: pertamax lalu variabel suhu $40,50,60,70{ }^{\circ} \mathrm{C}$ dan variabel putaran mesin 1500, 2000, 2500, 3000, 3500, 4000, 4500, 5000 (Rpm).

\section{Variabel Terikat}

Variabel terikat adalah hasil yang diinginkan dari pemberian variabel bebas. Dalam penelitian ini yang menjadi variabel terikatnya yaitu: emisi gas buang.

Pada penelitian ini akan menggunakan variabel bebas variasi jenis bahan bakar yaitu: pertamax lalu variabel suhu $40,50,60,70{ }^{\circ} \mathrm{C}$ dan variabel putaran mesin 1500,2000 , 2500, 3000, 3500, 4000, 4500, 5000 (Rpm). Variabelvariabel ini digunakan secara bergantian untuk lihat hasilnya berdampak pada emisi gas buang. Untuk penggunaan variabelnya sendiri seperti bahan bakar pertamax dipanasi sampai suhu $\left(40,50,60,70{ }^{\circ} \mathrm{C}\right)$ lalu putaran yang diambil untuk gas buang $(750,1000,2000,3000,4000$, dan 5000 rpm).
D. Spesifikasi Kendaraan

Tabel 1. spesifikasi kendaraan

\begin{tabular}{|l|l|}
\multicolumn{2}{|l|}{ Spesifikasi Kendaraan } \\
Jenis Mobil & Mini bus / Pick up \\
\hline Tipe Mesin & $7 \mathrm{k} ;$ OHV ; 1800cc \\
\hline Diameter x Langkah & 80,5 x $87,5 \mathrm{~mm}(7 \mathrm{k})$ \\
\hline Sistem Suplay BB & Karburator \\
\hline Transmisi & Manual 5 Kecepatan \\
\hline Tenaga Maksimal & 72 hp / 4.600 rpm \\
\hline Torsi Maksimal & 139 hp / 4.600 rpm \\
\hline Rasio konsumsi BB & 1 banding 6 \\
\hline Topspeed & $100 \mathrm{~km} / \mathrm{jam}$ \\
\hline
\end{tabular}

\section{HASIL Dan ANALSIS}

Penelitian ini dilakukan dengan menggunakan bahan bakar pertamax, pemanasan bahan bakarnya menggunakan air radiator yang mengalir keluar dari dalam mesin setelah melakukan proses pendinginan serta untuk melihat putarannya menggunakan tachometer. Setelah mendapatkan data maka data itu dibuat dalam bentuk grafik agar lebih mudah menganalisanya, untuk data emisinya penulis mengambil $\mathrm{CO}, \mathrm{CO}^{2}, \mathrm{HC}$, dan $\mathrm{O}^{2}$. Pengambilan data dilakukan sebanyak tiga kali, lalu dari data tersebut dibuat rata-rata setelah itu data rata-rata ini yang digunakan untuk membuat grafiknya. Tampilan grafik inilah yang akan dianalisis untuk mengetahui efek dari pemanasan bahan bakar tersebut.

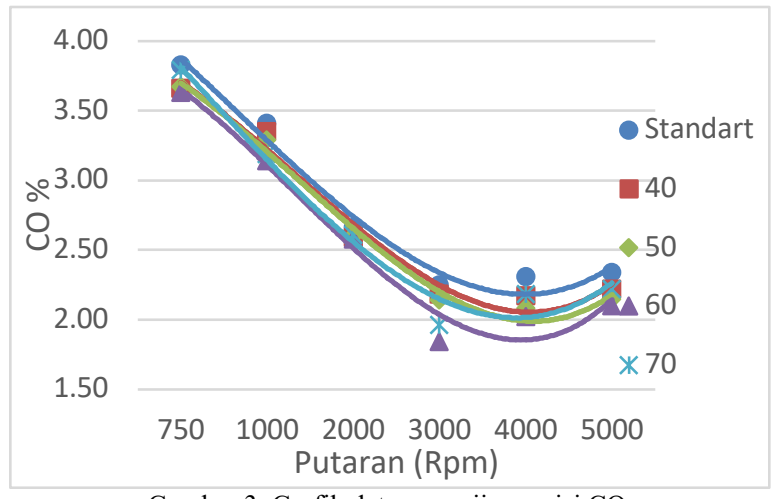

Gambar 3. Grafik data pengujian emisi CO

Berdasarkan gambar diatas dapat diketahui bahwa setelah penggunaan alat pemanas bahan bakar jenis pertamax kadar CO yang dihasilkan lebih rendah daripada hasil emisi CO tanpa menggunakan pemanas bahan bakar. Hal ini bisa disebabkan dengan memanaskan bahan bakar akan menyebabkan viskositas menurun sehingga dapat menyebabkan pengkabutan bahan bakar semakin baik dan menyebabkan pembakaran terjadi dengan sempurna, dari pembakaran yang semakin sempurna ini maka akan mengurangi emisi yang bersifat racun. 


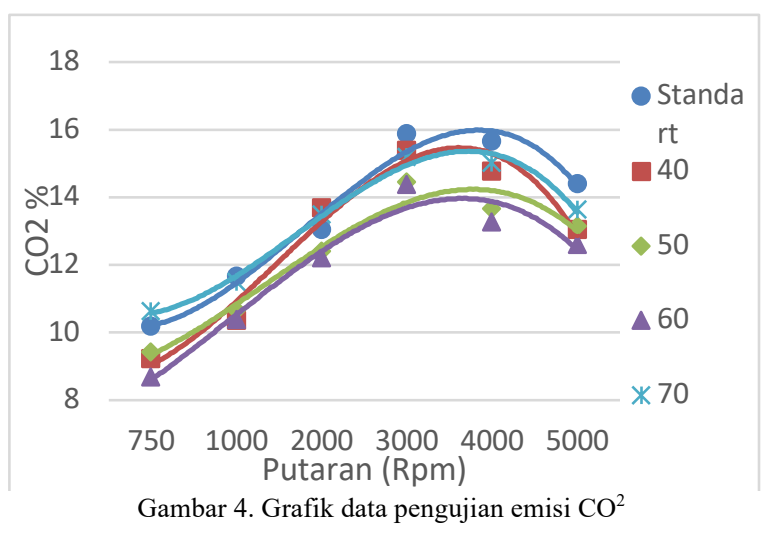

Berdasarkan gambar diatas dapat diketahui bahwa setelah ada pemanasan bahan bakar dengan jenis pertamax kadar $\mathrm{CO}^{2}$ yang dihasilkan lebih rendah daripada hasil emisi $\mathrm{CO}^{2}$ tanpa menggunakan pemanas bahan bakar.

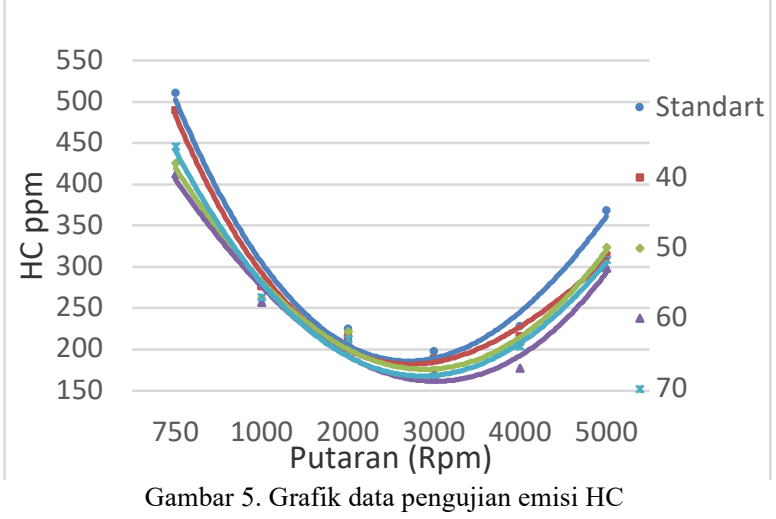

Berdasarkan gambar diatas dapat diketahui bahwa setelah ada pemanasan bahan bakar dengan jenis pertamax kadar HC yang dihasilkan lebih rendah dari pada kadar emisi $\mathrm{HC}$ yang tidah menggunakan pemanas bahan bakar. Emisi HC terendah terjadi pada suhu 60 derajat, hal ini terjadi karena pada suhu tersebut merupakan suhu dengan pemanasan terbaik dan tidak mempengaruhi periode pembakaran dan dapat menyebabkan pembakaran yang sempurna.

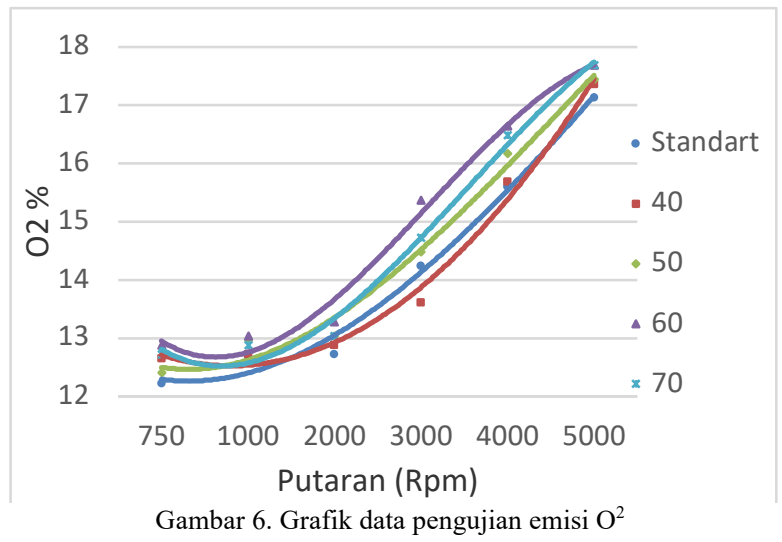

Berdasarkan gambar diatas dapat diketahui bahwa setelah ada pemanasan bahan bakar dengan jenis pertalite kadar $\mathrm{O}^{2}$ yang dihasilkan lebih tinggi dari pada kadar emisi $\mathrm{O}^{2}$ yang tidah menggunakan pemanas bahan bakar. Hasil yang didapatkan dari pembacaan grafik di atas emisi $\mathrm{O}^{2}$ tertinggi berada pada suhu 60 derajat.

\section{KESIMPULAN DAN SARAN}

Dari hasil penelitian yang telah dilakukan dapat diambil kesimpulan sebagai berikut :

Dapat dilihat dari hasil yang telah didapatkan bahwa dengan penggunaan pemanas bahan bakar ini telah menurunkan kadar emisi gas buang yang bersifat racun, pemanasan yang terbaik untung penurunan kadar emisi gas buang terdapat pada suhu $60^{\circ}$.

Untuk penelitian selanjutnya dapat membuat alat yang dapat menjaga suhu secara konsisten, serta dapat mengunakan alat tambahan berupa pemanas udara agar pemanasan yang terjadi pada bahan bakar dan udara dapat membuat campuran semakin sempurna.

\section{DAFTAR PUSTAKA}

[1] Gumulang D C, Wijayanto D S, Bugis H. 2016. Pengaruh Pemanasan Suhu Bahan Bakar dan Penambahan Biodiesel dalam Solar terhadap Opasitas Mesin Diesel Mitsubisi L300, Surakarta: Universitas Sebelas Maret.

[2] Kristanto, Ir. Philip. 2015. Motor Bakar Torak - Teori dan Aplikasinya. Yogyakarta: CV. Andi Offset.

[3] P Zakarias, M Pancoko. 2011. Perekayasaan Heat Exchanger Sebagai Pemanas Umpan UF6 Ke Reaktor Rotary Kiln.Tangerang Selatan: PUSPITEK Serpong.

[4] Romadlon S A, Siregar H I. 2013. Penambahan Pemanas Campuran Udara Dan Bahan Bakar Terhadap Performa Dan Emisi Mesin 1 Silinder, Surabaya: Universitas Negeri Surabaya.

[5] Saputro Y A, Sudibyo C, Wijayanto D S. 2011. Pengaruh Pemanasan Bahan Bakar Bensin Melalui Pipa Kapiler Bersirip Transversal Di Dalam Upper Tank Radiator Dan Putaran Mesin Terhadap Emisi Gas Buang Co Dan Hc Pada Mobil Toyota Corona, Surakarta: Universitas Sebelas Maret.

[6] Sabarudin S. 2012. Pengaruh Pemanasan Bahan Bakar Dengan Radiator Sebagai Upaya Meningkatkan Kinerja Mesin Bensin, Proton, vol. 4, no. 1, hal. 44-48.

[7] Sugiarti. 2009. Gas Pencemar Udara Dan Pengaruhnya Bagi Kesehatan Manusia. Jurnal Chemica Vol. 10. No. 1. 2009. Hal 50-58. 